\title{
Current synthetic overview on spinal cord injury epidemiological data
}

\author{
Ioana ANDONE ${ }^{1,2}$, Aurelian ANGHELESCU ${ }^{1,2}$, Cristina DAIA ${ }^{1,2}$, Gelu ONOSE ${ }^{1,2}$ \\ ${ }^{1}$ Teaching Emergency Hospital „Bagdasar-Arseni“ (TEHBA), Bucharest, Romania \\ ${ }^{2}$ „Carol Davila“ University of Medicine and Pharmacy, Bucharest, Romania
}

\begin{abstract}
Aim. To have updated information on the epidemiology of spinal cord injury (SCI) is required for developing an adequate and effective related health policy strategies and consequent contextual decisions making regarding this category of patients and also for planning and implementing SCI prevention education and measures. Accordingly, the rationale of this article is to provide a systematic overview of the literature regarding SCI epidemiology.

Material and methods. We reviewed epidemiological published reports and searched on internet specifically databases, from different centres, worldwide, about SCI, collecting descriptive data for properly estimating the incidence, prevalence, and/ or causes of SCI.

Results. The global annual incidence rate is considered to be 23 cases of Traumatic Spinal Cord Injury (TSCI) per million (179,312 new cases per annum - results provided by World Health Organisation's (WHO) in 2007). Prevalence per million inhabitants varies quite largely among statistics in different countries (from 280 in Finland to 681 in Australia, 755 in the United States of America or maybe even more, and even bigger in Canada). Men more commonly suffer from this kind of pathology and the direction of SCI evolution is to have a higher cord lesion level (more tetraplegics than paraplegics) and age at injury.

Conclusion. Even if the results of this literature review showed that the SCI incidence and prevalence are rising, they did not suffer significant changes in the last three decades of time. The prevalence surveys remain poor, mainly because a basic requirement for having correct and appropriately updated figures would need national and or regional electronic dedicated registers of evidence, and this is not a situation frequent enough. But the incidence studies from USA and Europe have been increased in the last years. This article asserts the need for improving the SCI data standardised collection in many countries, especially in the ones from low developed or emergent areas.
\end{abstract}

Keywords: spinal cord injury, incidence, prevalence, epidemiology

Abbreviations:

$\mathbf{S C l}=$ Spinal Cord Injury

USA = United States of America

$\mathbf{T S C l}=$ Traumatic Spinal Cord Injury

WHO = World Health Organisation
TEHBA = Teaching Emergency Hospital "Bagdasar-Arseni“

EU = European Union

$\mathbf{N T S C l}=$ Non-Traumatic Spinal Cord Injury 


\section{INTRODUCTION}

Spinal cord injury $(\mathrm{SCl})$ is a neurological condition that usually determine important loss of basic functions (mobility, sensitivity, micturition and/or defecation control etc) (1-4) being divided in two main types of lesion i.e. complete and incomplete and having often devastating lifelong sequels. The most common severe consequences of this condition are complete: tetraplegia and paraplegia.

Regarding epidemiology of $\mathrm{SCl}$ there are considerable research works in the last 40 years (5-8) but because their important limitations (in duration, not continuing in time, loss of information from state registries) the evaluation of international trustworthy $\mathrm{SCl}$ databases on incidence and (especially) prevalence became more difficult to be done. (9)

In a short digression, we emphasize that during 2006-2008, the Neuro-Rehabilitation Clinic Division of the Teaching Emergency Hospital „Bagdasar-Arseni“ (TEHBA) led by Prof. G. Onose as Project Director, deployed and carried out an excellency scientific research project entitled „Initiation of a National Informatical Network for dynamic clustering of patients with Spinal Cord Injury, dedicated to improve their quality of life, by aiming the eficientisation of the specific medico-social services, in transition" (acronym: R.I.S.C.I. -Romanian Informatics on $\mathrm{SCl}$ ).

Within this project there has been achieved also a partially automatically updating database, including by dynamic clustering. This intended national database could store information (secured, according to actual laws); yet, although including patented by the Romanian State Office for Inventions and Marks (registered No: RO 201100006 - „Interactive integrated system for collecting and managing biomedical data dedicated to advanced patients' dispensary") this has still not been implemented, pending on approval from the Social Medical Insurance System. Consequently, although initiation of such a network - warmly encouraged by the Leadership of the International Spinal Cord Society (ISCOS) - through wide-spreading specific information, would hopefully contribute to improve knowledge on chronic post $\mathrm{SCl}$ patients' situations, we do not currently have an electronic register with such individuals. (10)

The damage of the spinal cord can be done by trauma or by other causes like: degenerative pathology, tumours, infections, multiple sclero- sis, etc., and so, they can be split in two main categories: Traumatic Spinal Cord Injury (TSCl) and Non-Traumatic Spinal Cord Injury (NTSCI). From epidemiological point of view, the second group of such lesions, even if more frequently met, with higher incidence than $\mathrm{TSCl}$, are less studied (possible because of the non-concordance on the definitions of NTSCl or what pathology should be covered by such diagnosis) (9). Therefore, we will refer in this article particularly on $\mathrm{TSCl}$.

\section{STUDY DESIGN AND AIM}

Accordingly, in this work will be assessed a number of aspects regarding epidemiology (incidence, demographic aspects of these cases: age, gender, causes of injury, life expectancy, prevalence) of $\mathrm{SCl}$ based on a systematic review of the specific literature, in order to improve being necessary more effective ways - its prevention strategies and endeavours.

An important reason to quest and know the current incidence and prevalence of $\mathrm{SCl}$ is connected to the bio-psychological and socio-economical impact of such devastating conditions over time, especially related to their irreversible consequences. (11)

\section{MATERIAL AND METHODS}

We have analyzed relevant epidemiological surveys on $\mathrm{SCl}$ using an extensive literature review (based on important published reports and internet sites of $\mathrm{SCl}$ organisations, Google Scholar, using a number of key words) in order to provide recent and specific descriptive information.

Incidence values may show $\mathrm{SCl}$ level of control, including based on a good or poor prevention strategy and achievements. (11) An international comparison survey from 1995, showed that prevalence studies are fewer than incidence ones regarding $\mathrm{SCl}$ (12) and the same situation persists nowadays.

In 2005 it could be estimated that all over the world were around 2.5 million $\mathrm{SCl}$ persons, with 130,000 and more, new cases reported each year. $(13,14)$

In 2007 the overall incidence rate, worldwide, was evaluated at 23 new cases of TSCI per million yearly (179312 cases per annum) with a regional distribution of: 40 in North America, 16 in Europe, 15 in Australia. Other regional data vary between 21-25 in Asia, between 19-25 in Latin America and 21-29 in Africa. (15) 
Including in respect to $\mathrm{SCl}$, the closest to reality and updated statistics are to be found in the United States of America (USA) - so, we will detail here some current information from this zone (16). Also, it must be mentioned that, for a period of more than ten years, 1990-2000's till 2010 , probably because of some unsolved issues (lack of population basis etc), there have not been any valid incidence studies on $\mathrm{SCl}$. (17)

As shown above, the actual $\mathrm{SCl}$ incidence in USA is included between 25 to 59 new cases per million population per year (18-22), with an average of 40 , being almost 12,400 new cases in 2010. (23)

The overall assumption of $\mathrm{SCl}$ incidence in USA on the next decades is that this will be in continuous ascension from 13600 in 2020 to 17560 in 2050 (23) as it can be seen in Fig. 1.

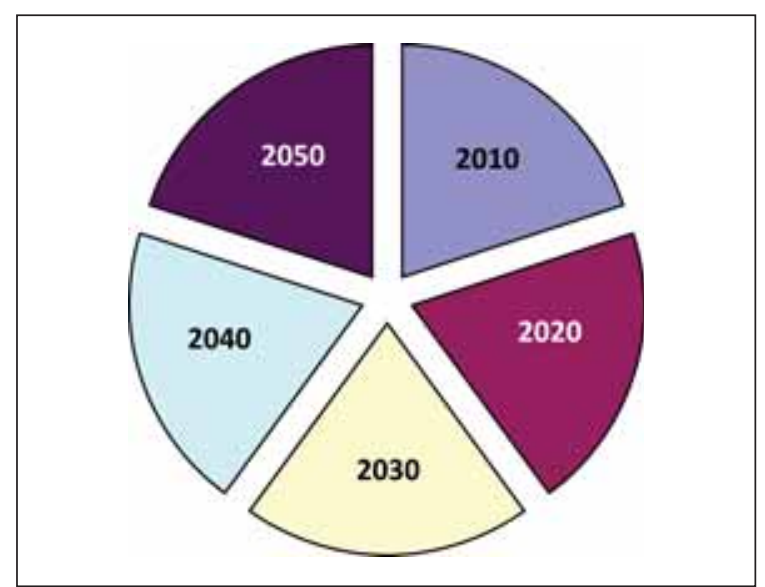

FIGURE 1. Graphical representation of the SCI incidence assumption in USA - synthesis based on data from (23)

Some detailed studies from British Columbia, Canada shows the incidence rates (Fig. 2) between 1995-2004 and $2010(24,25)$, not identical in trend with the data presented in Fig. 1.

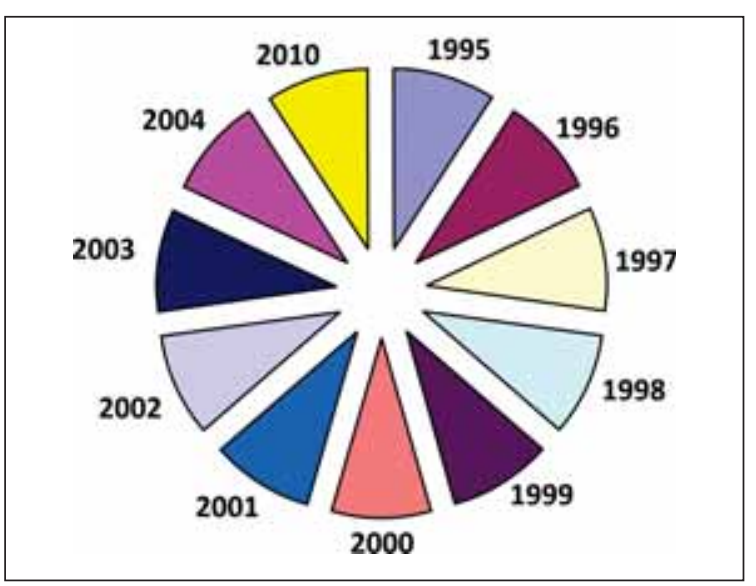

FIGURE 2. Graphical representation of the SCI incidence in Canada - synthesis based on data from $(24,25)$
The incidence of $\mathrm{SCl}$ is smaller on other continents than North America, because of the lower presence of some main possible related causes: violence, motor crashes, very long speed ways and/or respectively better driving practices/rules, but also greater mortality on impact etc. (9)

\section{CURRENT SCI EPIDEMIOLOGICAL DATA IN EUROPE, ROMANIA}

The total population of the European Union (EU) is now about 500 million people (26) and an important number of people are suffering after $\mathrm{SCl}$ in the related countries: around 330.000 individuals with 11.000 new $\mathrm{SCl}$ cases yearly. In Europe the average incidence calculated from 40 countries is 25 per million inhabitants yearly. (27) Herein below, there is emphasized the estimation of the WHO regarding the TSCl incidence by large geographic regions (Fig. 3).

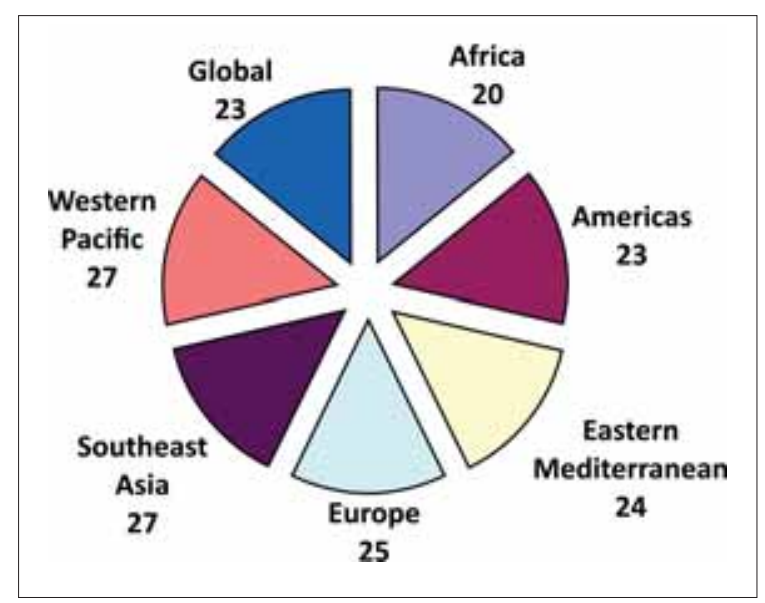

FIGURE 3. Graphical representation of the TSCI incidence estimated median by WHO region - synthesis based on data from (27)

In Romania, in 2008 there were 419 new cases of $\mathrm{SCl}$ patients with an incidence of $0.0190 \%$ 。 (10) the information being collected from the National Database of Inpatients. In 2009 it is mentioned in the same files a number of 407 such new cases (incidence of $0.0185 \%$ (28) the lowering value of incidence could be explained by the economic crisis and so, a decreased on motor vehicles sales). According to a current approach, in Romania there are 15,000 $\mathrm{SCl}$ people with an average age of 41.4 years. (10) These findings of ours support an above exposed assertion concerning the connection between (especially) the incidence of (poly) traumatic events - including of SCl type - and the economic consequent burden, but also the pre- 
traumatic occurrences one. All these data have been already published by us elsewhere. (29)

\section{INCIDENCE BY AGE AND GENDER}

The $\mathrm{SCl}$ patients are largely more frequent men, with an incidence of three to four times higher than women. (8) Beginning with the 2000s, (9) the incidence rate in men decreased slowly: from $80.9 \%$ in seventies to $77.1 \%$ nowadays $(8,9)$ a possible explanation of this lowering percentage in men, (15) may be the growing of women proportion in driving vehicles/ thus participating to traffic at a greater extent.

The $\mathrm{SCl}$ incidence by age at injury have two peaks one at late teens and young persons and the other one after 60 year's old $(18,21,30)$. In the USA the mean age enhanced and between 2005-2008 became 37.1 years comparing to 28.3 years in the 1970 s (31); this may be according to the accelerated global demographic aging (including) in the USA. (16)

\section{INCIDENCE BY CAUSE}

It is well known that being careful at work and at play and using all the safety driving rules, can protect for a possible $\mathrm{SCl}$, but the specific preventing strategy can be still improved by having an accuracy in the aetiology of injury, too. $(8,32)$ The more frequently met causes that can determine a TSCl are: motor crashes - the most common in USA $41 \%$ to $45 \%$ (31) and Canada $(24,33)$, violence acts/ assaults, falls - that are the leading cause of $\mathrm{SCl}$ in elderly $(8,32)$, sports accidents, work-related incidents, natural disasters etc.

To be mentioned that, regarding violence mainly gunshot - its share during the last three decades followed a sinuous trend: from 13.3\% prior and in the first third of this period, to almost $1 / 4(24.8 \%)$ of $\mathrm{SCl}$ in the 1990's and then back down to $15 \%$, since the second half of the last decade. (16)

\section{CONCERNING THE OCCUPATIONAL MATTER}

$57.3 \%$ of such patients were employed at the time of their $\mathrm{SCl}$; this proportion appears severely decreased $(11.6 \%)$ at one year after the injury, but enhances, in average, more than three times (35.2\% - tetraplegics, with $10 \%$ less than paraplegics); yet, almost half of the post $\mathrm{SCl}$ persons still never succeeded to come back to work and it keeps like this, for the following 30 years. (16)

\section{PREVALENCE}

Prevalence is estimated, in 2010, in the USA, between 232,000 and 316,000 (approximately 265,000 ) persons with $\mathrm{SCl}$ (higher than around five years previously: 755). (11) Tetraplegia is met in $55.8 \%$ (most of them incomplete $-39.5 \%$, vs. only $16.3 \%$ complete - incomplete tetraplegia being the most frequent such neurologic/ dysfunctional category) and $42.8 \%$ have paraplegia $(21.7 \%$ incomplete and $21.1 \%$ complete; the favorable trend: increase of incomplete to the detriment of complete - especially for tetraplegia - is found in the last $1^{1 / 2}$ decade; yet, less than $1 \%$ of post $\mathrm{SCl}$ individuals succeed to become AIS E at discharge. (34)

In Canada, there is the biggest number of cases of traumatic $\mathrm{TSCl}$ per million in a given year estimating the higher prevalence of $\mathrm{SCl}$ as 1,298 per million. (32)

In Sweden the TSCl prevalence was estimated to be 227 and in Finland, 280 individuals. (32) In India, the TSCl prevalence was reported to be 236 (35) and in Australia 681 (36). Current surveys showed 112 cases in Chile (37) and between 35.1-41.9 in Norway. (30)

As $\mathrm{SCl}$ frequently occur in (poly)traumatic situations, about half of all cases have, at least initially, other lesions, too. $(38,39)$

The mortality: (crude) death rate following $\mathrm{SCl}$ is big enough - mainly in the first year(s) being significantly higher (for instance, in the first 12 years after $\mathrm{SCl}$ this is more than ten folds $-9.3 \%(40)$ the general one $-8.8 \%$ (41), particularly for those severely injured (16). The most current and common causes of death in $\mathrm{SCl}$ population are: septicaemia, pulmonary emboli, pneumonia. (40) The renal failure rate of death decreased in the last four-five decades because of the neurogenic bladder advanced management. (16)

Over the last about 3-4 decades, there has been a decline at almost the half (40\%) in mortality during the first 2 years after injury. But, after this initial - considered critical - period, the decrease in mortality, seen on long-term, wasn't significant anymore. (42). Over time (after the first two years following $\mathrm{SCl}$ (42) mainly nowadays, it is considered that life expectancy in post $\mathrm{SCl}$ survivals is overall, slightly lower than in non-injured individuals. (16)

Average length of initial - in acute - hospitalization decreased to half (from 24 days, until 1979 , to 12 , since 2005) in the last about four decades and that of post acute/rehabilitation period, to less than half - from 98 to 37 days (16); this is probably, but not exclusively, due to 
both, the growing proportion of incomplete $\mathrm{TSCl}$ - certainly including with the contribution of some essential primary prevention of technical and regulatory kinds, such as for instance: improved security facilities in cars to be equipped with (airbags) and mandatory wearing for bikers/motor bikers - and improvement of integrated, comprehensive approaches, including in such conditions, within contemporary general medical advancements.

Average duration of hospitalization, as well as number of re-admissions/year (events seen in $1 / 3$ to $1 / 2$ of all post $\mathrm{SCl}$ individuals) are longer, respectively, more frequent, in complete than in incomplete patients. $(16,38)$

The related direct costs/economic burden for post $\mathrm{SCl}$ people, their families and society, and the indirect ones - that were estimated to $\$ 66,626$ per year in December 2010 (38) - are significantly differing by injury's level and severity and based on its long-term associated pathology, respectively by level of qualification, pre-injury employment profile and - again - severity of injury). $(16,43)$

One must notice the constant augmentation (about twice) of the average expenses per year and the estimated lifetime costs between 2004 and 2010 (without a spectacular improvement of the survival duration).

We present below in Fig. 4, a short questionnaire filled in, with some information about the $\mathrm{SCl}$ heath system, in the Teaching Emergency Hospital „Bagdasar-Arseni“, The National Centre of Neuro-Rehabilitation and also The National Reference Centre in Spinal Neurosurgery, in Bucharest, Romania. This questionnaire has been designed for a complex research aimed to understand and show the burden of care (individual vs. public) of $\mathrm{SCl}$ management, in 30 developed countries all over the world and sent to us by Prof. S. Aito, former Vice-President of the International Spinal Cord Society (ISCOS).

To be pointed out that Romania is a unitary state and therefore, the regulations, including with the sanitary legislation, are applicable throughout our country. Accordingly, we consider data resulting from the activity of the most important medical unit in Romania that approaches severe neuro-trauma, including with $\mathrm{SCl}$, might have some relevance, yet without expecting our answers could represent the related situation at the national level.

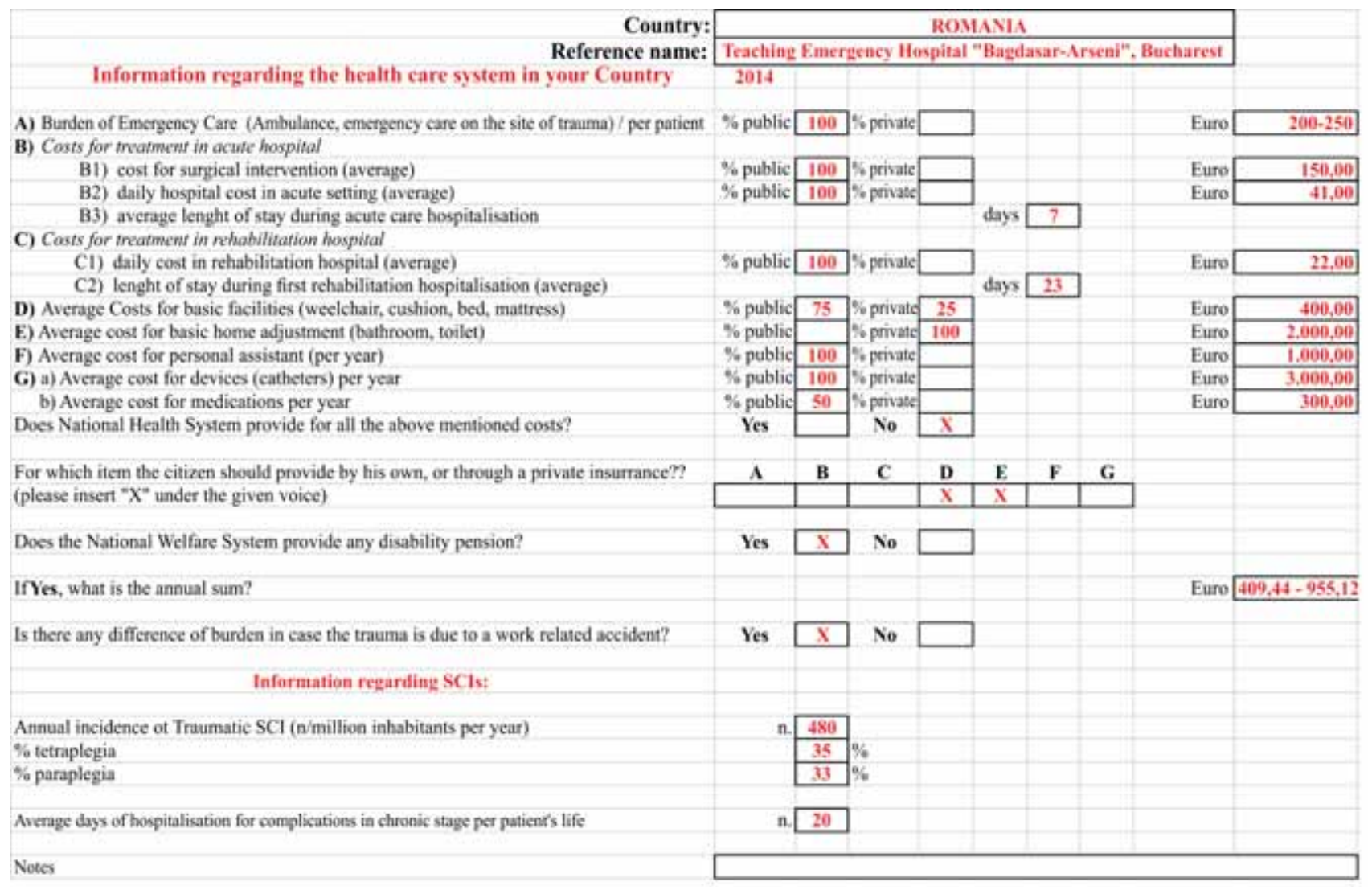

FIGURE 4. A short questionnaire with some information about the SCI health system from Teaching Emergency Hospital "Bagdasar-Arseni" 
Additionally, Prof. G Onose and some dedicated colleagues has contributed, around several months ago, to a large scale national campaign, organized by the Romanian Association for Work Safety and Health - with the support of a big media/broadcast company - for prevention of road traffic accidents: they have provided information regarding the devastating medical and social consequences of the possibly severe polytrauma, including with neurotrauma, following such kind of accidents. Accordingly, they have consistently contributed to the making of a short educational for related prevention, movie. To be specified the dimension of such an overall current educational endeavour: this is embedded within a systematically conceived national specific prevention campaign - to be deployed, till the end of this year, in six of the biggest towns of Romania, including with the Capital.

\section{CONCLUSIONS}

This article used significant epidemiological data in order to fulfil an integrative view on $\mathrm{SCl}$ incidence and prevalence.
Even if $\mathrm{TSCl}$ incidence and prevalence has been enhanced in several countries (especially the developed ones) worldwide, there are no major changes in the last three decades (10) and additional related studies must be undertaken including in purpose to improve the prevention priorities and actions. $(27,32)$

Important efforts should be done to prevent $\mathrm{TSCl}$ in both: young adult males and the ones caused by motor vehicle crushes and in older persons (focused on falls), respectively.

The results of this work showed that there are differences among geographic regions both in $\mathrm{TSCl}$ incidence and prevalence but the need for further research, especially in poor regions, may be overwhelmed by the financial costs and resource requirements for specific data acquisition systems. (27) Also, a better strategy to avoid discrepancies in incidence and prevalence among some geographic region is needed, in order to diminish the global gravity of this devastating condition. (32)

\section{REFERENCES}

1. Lin Vernon W., Cardenas Diana D., et al. Spinal Cord Medicine: principles and practice - Demos Medical Publishing, Inc., New York, 2003

2. Maynard F.M., Jr, Bracken M.B., Creasey G., Ditunno J.F. Jr, Donovan WH et al. International Standards for Neurological and Functional Classifcation of Spinal Cord Injury, Spinal Cord, 1997, 35: 266-274

3. Dahlberg A., Perttila I., Wuokko E. et al. Bladder management in persons with spinal cord lesion, Spinal Cord, 2004, 42:694-698

4. Sørensen F.B., Sønksen J. Sexual function in spinal cord lesioned men - Spinal Cord, 200, 39:455-470

5. Krauss J.F., Franti C.E., Reggins R.S., Richards D., Borhani N.O. Incidence of traumatic spinal cord lesions, J Chron Dis 1975, 28: 471-492

6. Griffin M.R., Optiz J.L., Kurland L.T., Ebersold M.J., O'Fallon W.M. Traumatic $\mathrm{SCl}$ in Olmsted Country, Minnesota, 1935, 121:884-895

7. Braken M.B., Freeman D.H., Hellenbrand K. Incidence of acute traumatic hospitalised spinal cord injury in the United States, 1970-1977, Am J Epidemiol 1981,113:615-622
8. DeVivo M.J. Epidemiology of traumatic spinal cord injury: trends and future implications, Spinal Cord, 2012, 50(5):365-372

9. DeVivo M.J. Epidemiology of traumatic spinal cord injury. In: Lin V.W. (ed). Spinal Cord Medicine Principles and Practice. Demos Medical Publishing: New York, NY, 2010, 78-84

10. Onose G., Anghelescu A., Georgescu F., et al. Initiation of a National Informatics Network for Patients with Sequels after Spinal Cord Injury, Report at the 5th Annual Congress of the European Spinal Cord Injuty Federation (ESCIF), Vienna/ Austria, 2009

11. Wyndaele M., Wyndaele J.J. Incidence, prevalence and epidemiology of spinal cord injury: what learns a worldwide literature survey?, Spinal Cord (2006) 44, 523-529

12. Blumer C.E., Quine S. Prevalence of spinal cord injury: an international comparison. Neuroepidemiology 1995; 14: 258-268.

13. Thuret S., Moon L.D.F., Gage F.H. Therapeutic interventions after spinal cord injury, Nature Reviews Neuroscience, 7: 628-643, 2006
14. http://www.campaignforcure.org/index.php/ general-information

15. Lee B.B., Cripps R.A., Fitzharris M., Wing P.C. The global map for traumatic spinal cord injury epidemiology: update 2011, global incidence rate, Spinal Cord (2014) 52, 110-116; doi:10.1038/sc.2012.158

16. https://www.nscisc.uab.edu

17. Glick T. SCl surveillance: is there a decrease in incidence? J. Spinal Cord Med 2000; 23 (Suppl):61

18. Price C., Makintubee S., Herndon W., Istre G.R. Epidemiology of traumatic spinal cord injury and acute hospitalization and rehabilitation charges for spinal cord injuries in Oklahoma, 1988-1990, Am J Epidemiol. 1994 Jan 1;139(1):37-47.

19. Thurman D.J., Burnett C.L., Jeppson L., Beaudoin D.E., Sniezek J.E. Surveillance of spinal cord injuries in Utah, USA, Paraplegia. 1994 Oct; 32(10):665-9.

20. Surkin J., Smith M., Penman A., Currier M., Harkey H.L. 3rd, Chang YF, Spinal cord injury incidence in Mississippi: a capture-recapture approach, J Trauma. 1998 Sep; 45(3):502-4. 
21. Acton P.A., Farley T., Freni L.W., llegbodu V.A., Sniezek J.E., Wohlleb J.C. Traumatic spinal cord injury in Arkansas, 1980 to 1989, Arch Phys Med Rehabil. 1993 Oct;74(10):103540.

22. Johnson R.L., Gabella B.A., Gerhart K.A., McCray J., Menconi J.C., Whiteneck G.G. Evaluating sources of traumatic spinal cord injury surveillance data in Colorado, Am J Epidemiol. 1997 Aug 1;146(3):266-72.

23. http://www.census.gov/compendia/ statab/cats/population.html

24. Lenehan B., Street J., Kwon B., Noonan V., Zhang H., Fisher C.G., Dvorak M.F. The epidemiology of traumatic spinal cord injury in British Columbia, Canada. Spine 2012; 378:321-329.

25. Noonan V.K., Finas M., Farry A., Baxter D., Singh A., Fehlings M.B., Dvorak M.F. Incidence and prevalence of spinal cord injury in Canada: A national perspective. Neuroepidemiology 2012; 38:219-226.

26. http://epp.eurostat.ec.europa.eu/tgm/ table.do?tab = table\&language $=$ en\&pcode $=$ tps $00001 \&$ table Selection $=1 \&$ footnotes=yes\&labeling= labels\&plugin=1

27. Fitzharris M., Cripps R.A., Lee B.B. Estimating the global incidence of traumatic spinal cord injury. Spinal Cord, 2014, 52, 117-122

28. Address no. 602/17.03.2010 of the Romanian National School for Public Health, Management and Perfecting in the Sanitary Domain, Bucharest

29. Onose G., Haras M., Mureşanu D., Giuglea C., Chendreanu D. Integrative emphases on intimate, intrinsic propensity/ pathological processes-causes of self recovery limits and also, subtle related targets for neuroprotection/ pleiotropicity/ multimodal actions, by accessible therapeutic approaches-in spinal cord injuries, J Med Life. 2010 Aug 15; 3(3): 262-274. Published online 2010 Aug 25.

30. Hagen E.M., Eide G.E., Rehkand T., Gihus N.E., Gronning M. A 50-yaers follow-up of the incidence of traumatic spinal cord injuries in Western Norway, Spinal Cord 2010, 48: 313-318

31. DeVivo M.J., Chen Y. Trends in new injuries, prevalent cases, and aging with spinal cord injury. Archives of Physical Medicine Rehabilitation 2011; 92: 332-338

32. Furlan J., Krassioukov A., Miller W.C., Trenaman L.M. Epidemiology of Traumatic Spinal cord Injury. In Eng J.J., Teasell R.W., Miller W.C., Wolfe D.L., Townson A.F., Hsieh J.T.C., Connolly S.J., Noonan V.K., Loh E., McIntyre A., editors. Spinal Cord Injury Rehabilitation Evidence, 2014 Version 5.0. Vancouver: p 1-121 http://www. scireproject.com/rehabilitation-evidence/epidemiology/incidence-and-prevalence-of-sci-continentand-country/prevalence

33. Dryden D.M., Saunders L.D., Rowe B.H., May L.A., Yiannakoulias N., Svenson L.W., Schopflocher D.P. Voaklander D.C. The epidemiology of traumatic spinal cord injury in Alberta, Canada. Can J Neurol Sci 2003; 30: 113-121.

34. http://www.apparelyzed.com/statistics. $\mathrm{html}$

35. Razdan S., Kaul R.L., Motta A., Kaul S., Bhatt R.K. Prevalence and pattern of major neurological disorders in rural
Kashmir (India) in 1986, Neuroepidemiology. 1994;13(3):113-9.

36. O'Connor P.J. Forecasting of spinal cord injury annual case numbers in Australia, Arch Phys Med Rehabil. $2005 \mathrm{Jan} ; 86(1): 48-51$.

37. Correa G.I., Finkelstein J.M., Burnier L.A., Danilla S.E., Tapia L.Z., Torres V.N., Castillo J.C. Work-related traumatic spinal cord lesions in Chile, a 20-year epidemiological analysis, Spinal Cord. 2011 Feb;49(2):196-9. doi: 10.1038/sc.2010.71. Epub 2010 Jun 15

38. http://www.sci-info-pages.com/facts. $\mathrm{html}$

39. Onose G., Ciurea A., Anghelescu A., Mardare D.C., Mihăescu A.S. et al. The Teaching Emergency Hospital „Bagdasar-Arseni“/Physical \& Rehabilitation Medicine Clinic Division's Expertise in Neurotrauma Within Poly-trauma, Complex, Post-Acute Approach - Communication at the Swiss-Romanian Joint Symposium on Trauma Care, Bucharest/ Romania, 2008

40. DeVivo M.J., Black K.J., Stover S.L. Causes of death during the first 12 years after spinal cord injury, Arch Phys Med Rehabil., 74(3):248-254, 1993

41. http://www.medterms.com/script/main/ art.asp?articlekey $=2913$

42. Strauss D.J., DeVivo M.J., Paculdo D.R., Shavelle R.M. Trends in life expectancy after spinal cord injury, Arch Phys Med Rehabil., 87(8):10791085, 2006

43. http://blog.lib.umn.edu/devag002/ myblog/2011/04/ 